\title{
Prognostic Value of Labyrinthine 3D-FLAIR Abnormalities in Idiopathic Sudden Sensorineural Hearing Loss
}

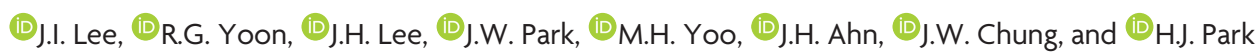

\begin{abstract}
BACKGROUND AND PURPOSE: According to recent research, modern MR imaging can detect the presense of abnormalities on labyrinthine. Our aim was to report the patterns and prognostic role of abnormal findings on labyrinthine imaging in patients with sudden sensorineural hearing loss.
\end{abstract}

MATERIALS AND METHODS: This study comprised 113 patients who were diagnosed with unilateral sudden sensorineural hearing loss and underwent 3T MR imaging, including pre-/postcontrast 3D fluid-attenuated inversion recovery and T1-weighted imaging. We analyzed abnormalities on MR imaging and correlated them with audiometric results.

RESULTS: Thirty-one (27\%) patients showed abnormal findings on labyrinthine MR imaging in the affected ear. The initial/final hearing levels of the MRI+ group $(91 \pm 25 / 73 \pm 27 \mathrm{~dB}$ hearing loss) were significantly worse than those of the MRI- group (69 $\pm 30 / 48 \pm 24 \mathrm{~dB}$ hearing loss). The incidence of abnormalities on labyrinthine MR imaging was significantly lower ( 3 of 40, $8 \%$ ) in 40 patients with initial mild-to-moderate hearing loss than in those with profound hearing loss (16 of 34, 47\%). Considering hearing improvement by the Siegel criteria, the rate of complete or partial recovery was significantly higher in the MRI- group (34\%) than in the MRI+ group (10\%). In patients with initial severe or profound hearing loss, the MRI- group showed greater hearing improvement ( $38 \pm 21 \mathrm{~dB})$ than the MRI + group $(23 \pm 22 \mathrm{~dB})$.

CONCLUSIONS: Abnormalities on labyrinthine MR imaging were found in $27 \%$ of patients with sudden sensorineural hearing loss. The initial hearing loss was worse in the MRI + group than in the MRI- group. In patients with initial severe and profound hearing loss, the presence of abnormalities on labyrinthine MR imaging indicated a poor prognosis.

ABBREVIATIONS: DPOAE = distortion product otoacoustic emissions; $\mathrm{HL}=$ hearing loss; $\mathrm{PTA}=$ pure-tone average; $\mathrm{SSNHL}=$ sudden sensorineural hearing loss

$\mathbf{S}$ dden sensorineural hearing loss (SSNHL) is caused by a variety of pathophysiologic mechanisms and can occur when cochlea or neural function or both are impaired. Viral infection and traumatic, neoplastic, immunologic, toxic, circulatory, and neurologic causes are well-known etiologic factors in 10\%-15\% of patients with SSNHL, but the cause is unknown in most cases. ${ }^{1}$ Although there are many causes of SSNHL, temporal bone histopathologic evidence indicates that SSNHL could be caused by

Received December 21, 2015; accepted after revision June 16, 2016.

From the Departments of Otolaryngology (J.I.L., J.W.P., J.H.A., J.W.C., H.J.P.) and Radiology (J.H.L.), Asan Medical Center, University of Ulsan College of Medicine, Seoul, Korea; Department of Radiology (R.G.Y.), Catholic Kwandong University International St. Mary's Hospital, Catholic Kwandong University College of Medicine, Incheon, Korea; and Department of Otolaryngology (M.H.Y.), College of Medicine, Kyungpook National University, Daegu, Korea.

J.I.L. and R.G.Y. contributed equally to this article.

Please address correspondence to Hong Ju Park, MD, PhD, Department of Otolaryngology, Asan Medical Center, University of Ulsan College of Medicine, 86 Asanbyeongwon-gil, Songpa-gu, Seoul, Korea 138-736; e-mail: dzness@amc.seoul.kr

http://dx.doi.org/10.3174/ajnr.A4901 viral cochleitis or cochlear neuritis, and these lesions are unlike those resulting from known vascular causes. ${ }^{2}$

MR imaging is frequently performed to evaluate patients with SSNHL, traditionally to identify brain lesions or retrocochlear lesions such as vestibular schwannoma. ${ }^{3}$ Several studies reported that new MR imaging sequences can evaluate labyrinthine abnormalities (the presence of intracellular and extracellular methemoglobin or increased protein content in the membranous fluid) by using 3D fluid-attenuated inversion recovery in patients with SSNHL $^{4-10}$ and can distinguish endolymphatic hydrops by volumetric quantification of MR imaging. ${ }^{11}$ These abnormal findings may also be a novel prognostic factor for SSNHL, but there are conflicting results about the prognostic value of abnormalities on labyrinthine MR imaging. ${ }^{6,9}$

The purpose of this study was to report the incidence of abnormalities on labyrinthine MR imaging in 113 patients with SSNHL and to evaluate the prognostic value of these abnormalities. 


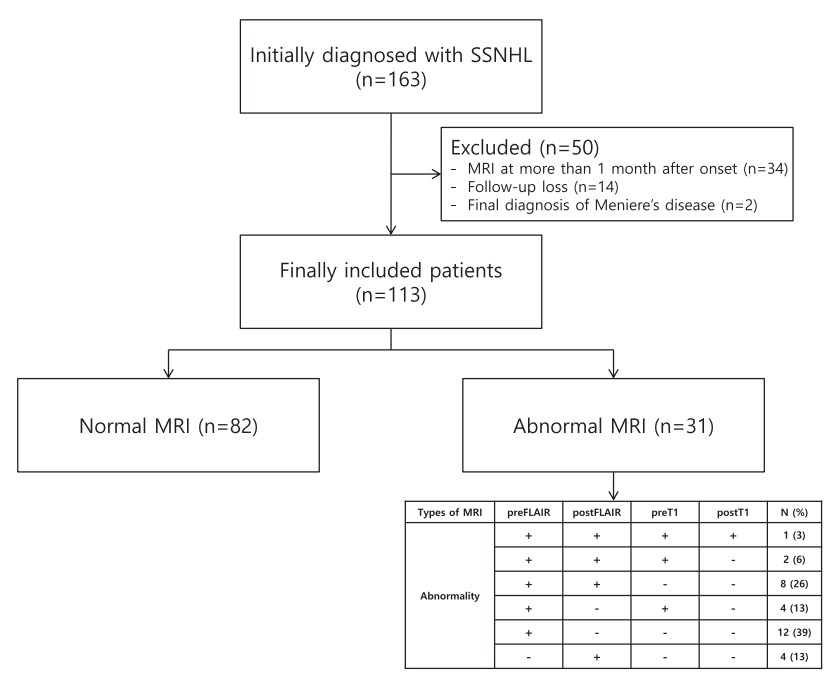

FIG 1. Study population excluded and enrolled in this study.

\section{MATERIALS AND METHODS Patients}

From July 2011 to June 2013, 163 patients were diagnosed with unilateral SSNHL and underwent 3T MR imaging, including pre-/postcontrast 3D-FLAIR and T1-weighted imaging. The criteria used to define SSNHL were the presence of unilateral sensorineural hearing loss of $\geq 30 \mathrm{~dB}$ over at least 3 contiguous audiometric frequencies developed during a period of a few hours up to 3 days, without any obvious cause. ${ }^{12}$ We excluded 34 patients who underwent MR imaging after $>1$ month from onset, 14 patients with loss to follow-up, and 2 patients diagnosed with Menière disease during follow-up. Finally, 113 patients were included in this study (Fig 1). The protocol was approved by the institutional review board of Asan Medical Center.

\section{Audiologic Evaluation and MR Imaging}

All patients underwent a physical examination; an otologic assessment, including an endoscopic examination of the tympanic membrane; and both pure-tone and speech audiometry. Hearing levels were evaluated with pure-tone audiometry (Madsen Orbiter 922; GN Otometrics, Taastrup, Denmark) in a sound-isolated chamber. Hearing loss (HL) was defined by the pure-tone average (PTA), calculated by using thresholds at $0.5,1.0,2.0$, and $4.0 \mathrm{kHz}$. Audiometric assessments were performed at the time of diagnosis, 1 month later, and then after steroid treatment; the last audiometric findings obtained $4.3 \pm$ 4.1 months (median, 3.0 months) after steroid treatment were considered the definitive posttreatment result.

The severity of the initial hearing loss was classified as mild (26-40 dB), moderate (41-55 dB), moderately severe (56-70 $\mathrm{dB})$, severe (71-90 dB), or profound (>90 dB). If the patient did not respond to the maximum sound level, we defined the threshold as the maximum level plus $5 \mathrm{~dB}$. After at least 1 month, the PTA was determined again for evaluation of the therapeutic effects. The degree of recovery was evaluated according to the Siegel criteria, ${ }^{13}$ as follows: complete recovery $=$ final hearing $<25 \mathrm{~dB}$ $\mathrm{HL}$; partial recovery $=$ gain $>15 \mathrm{~dB}$ and a final hearing of 25 to 45 $\mathrm{dB}$ HL; slight improvement $=$ gain $>150 \mathrm{~dB}$ and a final hearing of
$>45 \mathrm{~dB} \mathrm{HL}$; and no improvement $=$ gain $<15 \mathrm{~dB}$ and a final hearing of $>75 \mathrm{~dB}$ HL. All patients were treated with oral methylprednisolone, $48 \mathrm{mg} /$ day for 9 days, and then tapered during 5 days. Intratympanic steroid injections were administered to patients experiencing insufficient hearing gains after intraoral methylprednisolone therapy.

MR imaging was performed by using a 3T MR imaging system (Achieva; Philips Healthcare, Best, the Netherlands) with an 8-channel head coil. The protocols included coronal T1- and T2weighted turbo spin-echo, axial 3D T2-weighted, pre-/postcontrast 3D-FLAIR, and postcontrast T1-weighted imaging. For enhancement, Gd-DOTA (Dotarem; Guerbet, Aulnay-sous-Bois, France) at $0.2 \mathrm{mmol} / \mathrm{kg}$ of body weight was used, and axial 3DFLAIR images were acquired with a time delay of 7 minutes. The delay between SSNHL onset and MR imaging was $9.7 \pm 8.0$ days (range, 1-30 days).

Axial 3D T2-weighted imaging was performed with the following parameters: $\mathrm{TR}=2000 \mathrm{~ms} ; \mathrm{TE}_{\text {eff }}=250 \mathrm{~ms}$; flip angle $=90^{\circ}$; number of signal averages $=2$; echo-train length $=70$; number of encoding steps $=300 ; \mathrm{FOV}=180 \times 180 \mathrm{~mm}$; matrix $=300 \times 300$ (reconstruction matrix $=512 \times 512)$; voxel size $=0.6 \times 0.6 \times 0.6 \mathrm{~mm}$; slab number $=1$; slab thickness $=40 \mathrm{~mm}$; section thickness $=1.2 \mathrm{~mm}$; spacing between sections $=0.6 \mathrm{~mm}$; acquisition time $=4$ minutes 58 seconds; and sensitivity encoding factor $=2$.

Axial pre-/postcontrast 3D-FLAIR MR imaging was performed with the following parameters: $\mathrm{TR}=8000 \mathrm{~ms} ; \mathrm{TE}_{\text {eff }}=280$ $\mathrm{ms}$; flip angle $=90^{\circ}$; number of signal averages $=1 ; \mathrm{TI}=2400 \mathrm{~ms}$; fat saturation $=$ spectral adiabatic inversion recovery; flip angle $=$ $90^{\circ}$; echo-train length $=80$; number of encoding steps $=300$; FOV $=180 \times 180 \mathrm{~mm}$; matrix $=300 \times 300$ (reconstruction matrix $=512 \times 512)$; voxel size $=0.6 \times 0.6 \times 0.6 \mathrm{~mm}$; slab number $=1$; slab thickness $=40 \mathrm{~mm}$; section thickness $=1.2$ $\mathrm{mm}$; spacing between sections $=0.6 \mathrm{~mm}$; acquisition time $=8$ minutes 48 seconds; and sensitivity encoding factor $=2$.

Axial postcontrast T1-weighted imaging was performed with the following parameters: $\mathrm{TR}=25 \mathrm{~ms} ; \mathrm{TE}_{\text {eff }}=4.6 \mathrm{~ms}$; flip angle $=30^{\circ}$; number of signal averages $=2$; echo-train length $=70$; number of encoding steps $=300 ; \mathrm{FOV}=180 \times 180 \mathrm{~mm}$; matrix $=300 \times 300$ $($ reconstruction matrix $=512 \times 512)$; voxel size $=0.6 \times 0.6 \times 0.6$ $\mathrm{mm}$; slab number $=1$; slab thickness $=40 \mathrm{~mm}$; section thickness $=$ $1.2 \mathrm{~mm}$; spacing between sections $=0.6 \mathrm{~mm}$; acquisition time $=3$ minutes 57 seconds; and sensitivity encoding factor $=2$.

Two neuroradiologists (R.G.Y. and J.H.L.) reviewed pre-/postcontrast 3D FLAIR images and pre-/postcontrast T1-weighted images to determine the presence of abnormalities on labyrinthine MR imaging in both labyrinths. They were blinded to the patient medical histories. The presence of any signal changes for the cochlea, vestibule, and semicircular canals was visually assessed and recorded separately as positive or negative (Fig 2). If there was any discrepancy between the decisions for the signal changes noted by the 2 readers, a consensus was achieved by discussion. The presence of contrast enhancement was defined as positive when comparisons of the pre- and post-contrastenhanced 3D FLAIR images and T1-weighted images showed a distinct linear or dotlike area of increased signal intensity within the cochlea, vestibule, or semicircular canals after contrast material injection. The presence of any signal changes in 

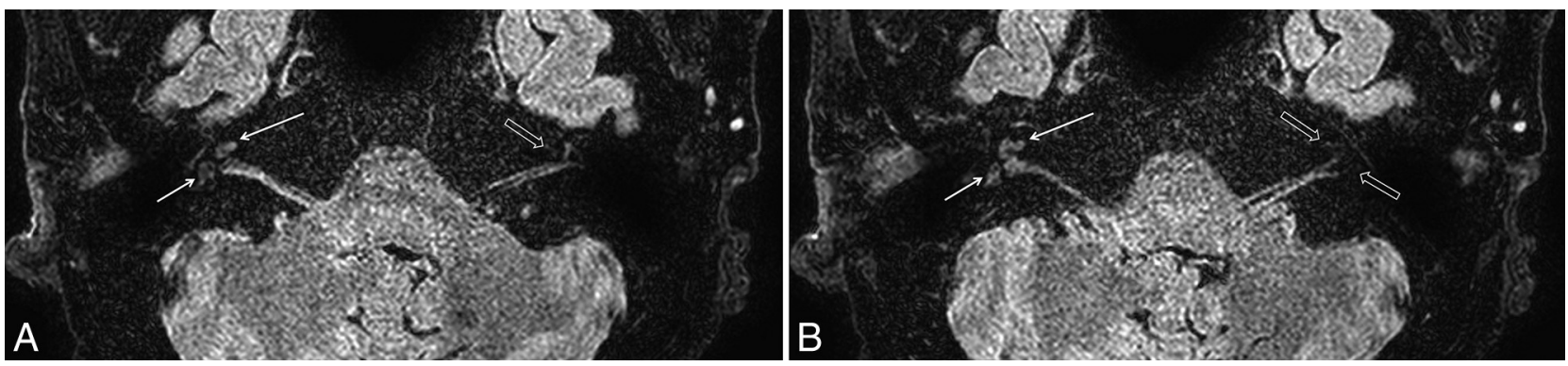

FIG 2. Precontrast axial scans of 3D-FLAIR MR imaging in right inner ear of a 63-year-old man with right sudden sensorineural hearing loss with vertigo. Bright signals (arrows) are visible only in the right cochlea and vestibule at the level of the basal turn $(A)$ and midturn $(B)$ of the cochlea and vestibule, not in the left healthy cochlea and vestibule (open arrows).

Table 1: Clinical and demographic characteristics of patients with SSNHL

\begin{tabular}{lcccc}
\hline & $\begin{array}{c}\text { All } \\
(\boldsymbol{N}=113)\end{array}$ & $\begin{array}{c}\text { MRI- Group } \\
(\boldsymbol{n}=\mathbf{8 2})\end{array}$ & $\begin{array}{c}\text { MRI+ Group } \\
(\boldsymbol{n}=31)\end{array}$ & $\boldsymbol{P}$ Value \\
\hline Mean age (yr) & $53 \pm 14$ & $53 \pm 14$ & $55 \pm 14$ & .634 \\
Sex (male/female) & $51: 62$ & $38: 44$ & $13: 18$ & .675 \\
DM (No.) (\%) & $11(10)$ & $7(9)$ & $4(13)$ & .490 \\
HTN (No.) (\%) & $27(24)$ & $20(24)$ & $7(23)$ & .840 \\
Vertigo (No.) (\%) & $30(27)$ & $21(26)$ & $9(29)$ & .713 \\
Tinnitus (No.) (\%) & $82(73)$ & $61(74)$ & $21(68)$ & .480 \\
Ear fullness (No.) (\%) & $53(47)$ & $39(48)$ & $14(45)$ & .820 \\
Initial visit after onset (days) & $7 \pm 10$ & $7 \pm 10$ & $9 \pm 9$ & .076 \\
MRI after onset (days) & $10 \pm 8$ & $10 \pm 8$ & $9 \pm 6$ & .804 \\
ITSI before MRI (No.) (\%) & $16(14)$ & $11(13)$ & $5(16)$ & .713 \\
\hline
\end{tabular}

Note:-DM indicates diabetes mellitus; HTN, hypertension; ITSI, intratympanic steroid injection.

Table 2: Initial and final audiologic results and classification by Siegel criteria in MRI+ and MRI- groups

\begin{tabular}{|c|c|c|c|c|}
\hline & $\begin{array}{c}\text { All Cases } \\
(N=113)\end{array}$ & $\begin{array}{c}\text { MRI- Group } \\
\quad(n=82)\end{array}$ & $\begin{array}{c}\text { MRI+ Group } \\
(n=31)\end{array}$ & $P$ Value \\
\hline Initial audiogram (mean) (dB HL) & $75 \pm 30$ & $69 \pm 30$ & $91 \pm 25$ & $<.001$ \\
\hline Severity of initial HL (No.) (\%) & & & & .005 \\
\hline Mild & $16(14)$ & $15(18)$ & $1(3)$ & \\
\hline Moderate & $24(21)$ & $22(27)$ & $2(6)$ & \\
\hline Moderately severe & $15(13)$ & $10(12)$ & $5(16)$ & \\
\hline Severe & $24(21)$ & $17(21)$ & $7(23)$ & \\
\hline Profound & $34(30)$ & $18(22)$ & $16(52)$ & \\
\hline Additional ITSI (No.) (\%) & $79(70)$ & $50(61)$ & $29(94)$ & .001 \\
\hline Final audiogram (mean (dB HL) & $55 \pm 27$ & $48 \pm 24$ & $73 \pm 27$ & $<.001$ \\
\hline Improvement of hearing ( $\Delta \mathrm{PTA}, \mathrm{dB})$ & $20 \pm 24$ & $21 \pm 23$ & $18 \pm 24$ & .964 \\
\hline Improvement by Siegel criteria (No.) (\%) & & & & .003 \\
\hline No improvement & $50(44)$ & $38(46)$ & $12(39)$ & \\
\hline Slight improvement & $32(28)$ & $16(20)$ & $16(52)$ & \\
\hline Partial recovery & 18 (16) & $17(21)$ & $1(3)$ & \\
\hline Complete recovery & $13(12)$ & $11(13)$ & $2(6)$ & \\
\hline
\end{tabular}

Note:- $\triangle$ PTA indicates difference of mean pre- and posttreatment PTA; ITSI, intratympanic steroid injection.
$\mathrm{MRI}+$ and MRI - groups, there were no significant differences in age, sex, underlying disease (diabetes mellitus, hypertension), or associated symptoms (Table 1). The average period from onset to initial visit and from onset to MR imaging examination of all patients was $7 \pm 10$ and $10 \pm 8$ days, respectively, which was also not significantly different between the 2 groups. In the MRI+ group, 27 patients showed high signal intensity in the affected inner ears on precontrast 3D-FLAIR images, 11 of whom also showed high signal intensity on gadolinium-enhanced 3D-FLAIR images in the affected ear. Moreover, 7 of 27 patients who were $\mathrm{MRI}+$ in precontrast $3 \mathrm{D}$ FLAIR images also showed high signals on precontrast T1-weighted images, one of whom exhibited high signals on both pre- and postcontrast T1-weighted images. High signals on only postcontrast 3D-FLAIR images were observed in 4 patients. No patients exhibited high signals in the contralateral intact ear. Twentynine patients showed high signals in the cochleae, and 20 of them showed high signals in the vestibule. Two patients exhibited high signals only in the vestibule or semicircular canal (1 each).

Patients were classified into 5 catego- the labyrinth was considered MRI+, and the absence of any high signal was considered MRI-.

\section{Statistical Analysis}

The results of audiologic findings in patients with MRI+ and MRI - were compared by using the Mann-Whitney $U$ test for continuous variables and the Pearson $\chi^{2}$ test for categoric variables. A $P$ value $<.05$ was considered statistically significant. Statistical analyses were conducted by using SPSS software (Version 14.0 for Windows; IBM, Armonk, New York).

\section{RESULTS}

Thirty-one (27\%) of 113 patients with SSNHL showed abnormalities on labyrinthine MR imaging in the affected ears. Between the ries on the basis of PTA: 16 patients with mild HL, 24 with moderate HL, 15 with moderately severe HL, 24 with severe HL, and 34 profound HL. The incidence of abnormalities on labyrinthine MR imaging was analyzed according to the initial hearing levels (Table 2 ). The abnormal rate was significantly lower $(8 \%, 3$ of 40$)$ in patients with initial mild-to-moderate HL than in patients with initial profound HL (47\%, 16 of 34$)$.

The initial/final hearing levels ( $91 \pm 25 / 73 \pm 27 \mathrm{~dB} \mathrm{HL})$ of the $\mathrm{MRI}+$ group were significantly worse than those $(69 \pm 30 / 48 \pm 24$ $\mathrm{dB}$ HL) of the MRI - group (Table 2). When one considers hearing improvement according to the Siegel criteria, the rate of complete or partial recovery in the MRI - group (34\%) was significantly higher than that (10\%) of the MRI+ group (Fig 3); however, the overall 
hearing improvement of the MRI+ group $(18 \pm 24 \mathrm{~dB})$ was not significantly worse than that of the MRI - group $(21 \pm 23 \mathrm{~dB})$.

When analyzing the data from the patients with SSNHL with the initial severe and profound HL $(n=58)$, the MRI+ group showed a significantly reduced improvement compared with that of the MRI- group. The degree of hearing improvement in patients in the MRI+ group $(23 \pm 24 \mathrm{~dB})$ was significantly lower than that of patients in the MRI- group $(38 \pm 27 \mathrm{~dB})$. Moreover, the final PTA of the MRI+ group $(80 \pm 27 \mathrm{~dB} H \mathrm{HL})$ was significantly higher than that of the MRI- group $(60 \pm 23$ dB HL) (Fig 4).

Ten patients showed low-frequency hearing loss at the initial PTA, according to the classification of Mazzoli et al. ${ }^{14}$ Only 1 patient (10\%) showed an MRI+ finding. By the Siegel criteria,

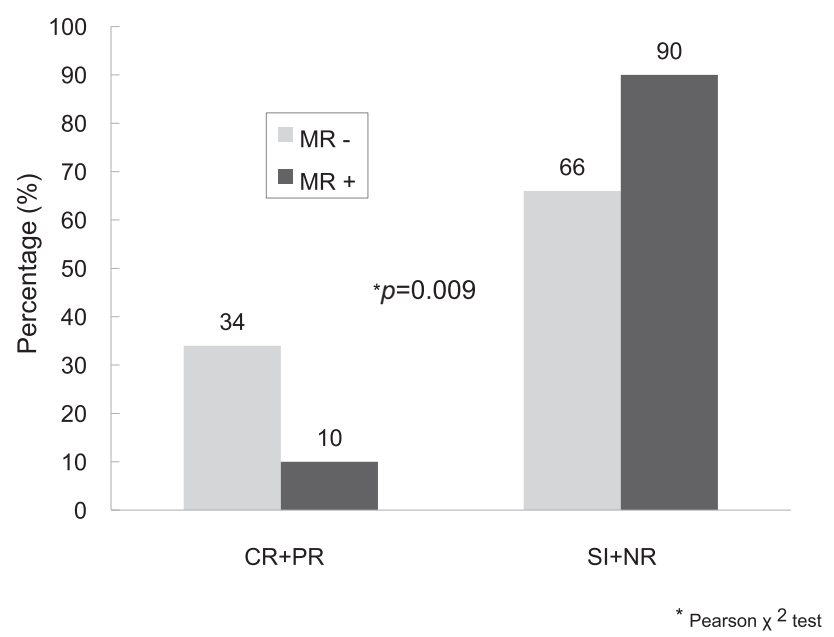

FIG 3. Hearing improvement according to the Siegel criteria in the $\mathrm{MRI}+$ and MRI - groups. CR indicates complete recovery; PR, partial recovery; SI, slight improvement; NR, no recovery.

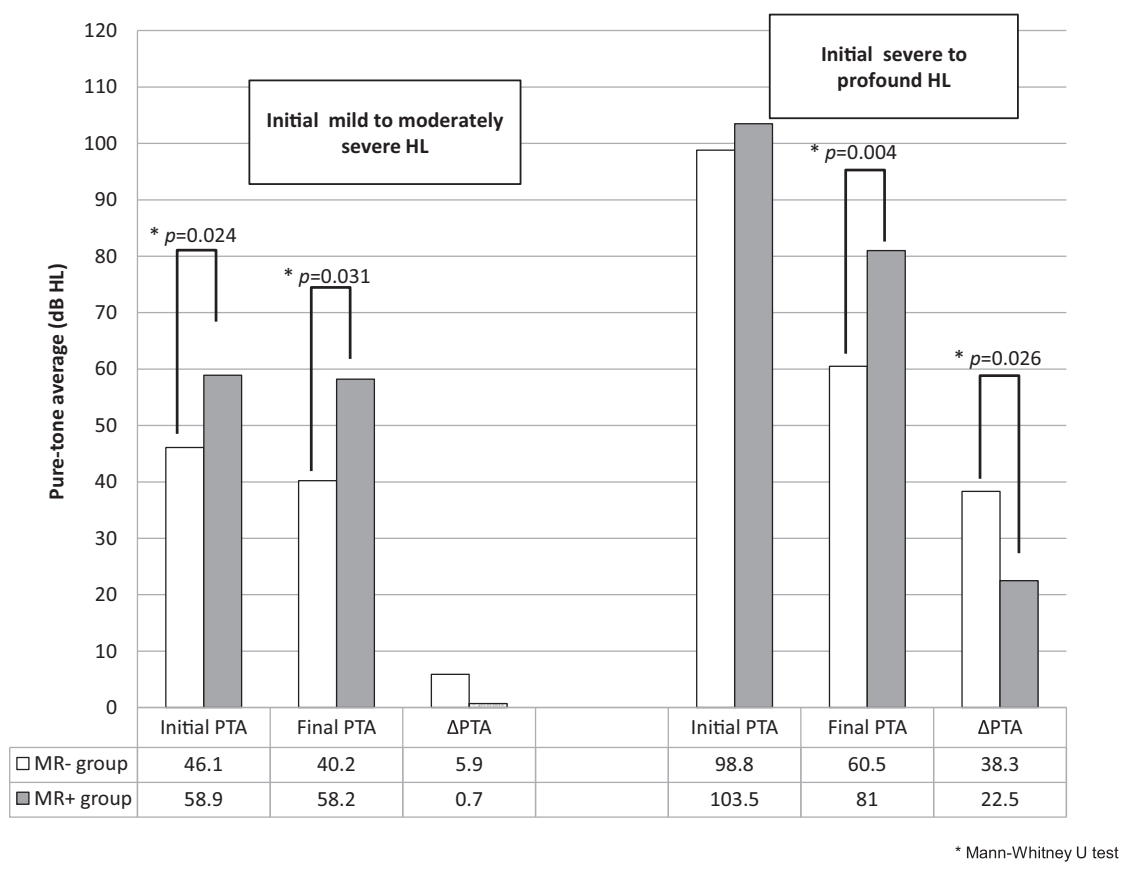

FIG 4. Initial pretreatment and final posttreatment audiologic findings and the improvement of hearing $(\triangle \mathrm{PTA})$ in the MRI - and MRI + groups according to the initial hearing loss. $\triangle \mathrm{PTA}$ indicates the difference of mean pre- and posttreatment.
$7(70 \%)$ recovered completely or partially, and another 3 $(30 \%)$ showed no improvement. Patients with the low-frequency type showed a low incidence of abnormal findings on MR imaging and a better prognosis compared with patients with other types.

\section{DISCUSSION}

Although contrast-enhanced MR imaging has been used to rule out retrocochlear lesions in patients with SSNHL, modern MR imaging can also detect the presence of abnormalities on labyrinthine MR imaging. It was previously reported that increased protein concentrations are characterized by high signal intensity on 3D-FLAIR imaging, ${ }^{5,8,10,15}$ which was reported to be more sensitive than T1- and T2-weighted MR imaging. ${ }^{6,7}$ Moreover, 3DFLAIR imaging can detect the breakdown of the blood-labyrinth barrier as an enhancement of fluid signal in the inner ear and/or nerve signal after gadolinium injection, owing to its high sensitivity to magnetic susceptibility. ${ }^{8,9}$ Typically, the perilymph and endolymph are isointense to CSF on all MR imaging sequences. It was reported that healthy subjects did not exhibit high signal intensity in the inner ear with or without gadolinium enhancement on 3D-FLAIR images until 10 minutes after gadolinium injection. $^{16}$

In our study, 3D-FLAIR provided a diagnostic sensitivity for $27 \%$ (31 of 113) of patients with SSNHL who were otherwise healthy. We observed high signal intensity in the affected ears only, not in the contralateral intact ears, confirming the high reliability of 3D-FLAIR MR imaging. Our abnormality rate on labyrinthine MR imaging (27\%) was similar to those (26\%-34\%) of previous reports, ${ }^{9,17}$ though others reported high abnormality rates $(57 \%-65 \%) .{ }^{6,7}$ We speculate that both inflammation and hemorrhage might increase the protein content, resulting in positive findings on 3D-FLAIR. Temporal bone histopathologic evidence indicated that SSNHL may be caused by viral cochleitis or cochlear neuritis rather than vascular etiologies. ${ }^{2}$ Intralabyrinthine hemorrhage might be differentiated from increased protein content when high signal intensities are observed in both T1 and 3D-FLAIR imaging. ${ }^{6,18}$ According to these criteria, intralabyrinthine hemorrhage could be suspected in $6 \%$ (7 of 113) of patients in this study. Whether the abnormalities on labyrinthine MR imaging indicate increased protein content induced by an inflammatory process or intralabyrinthine hemorrhage requires further clarification.

In the current study, initial hearing levels in the MRI+ group $(91 \pm 25 \mathrm{~dB}$ $\mathrm{HL}$ ) were significantly worse than those of the MRI - group (69 $\pm 30 \mathrm{~dB} \mathrm{HL})$; this finding suggests that extensive damage to the inner ear structures correlates with a positive result on 3D-FLAIR. The incidence of abnormalities on labyrinthine MR imaging was low $(3,8 \%)$ in 40 patients with initial mild-to-moderate 
HL and increased to $47 \%$ ( 16 of 34 ) in patients with profound HL, which was a significant difference. These findings are comparable with those of previous reports in which the initial PTA exhibited a good correlation with 3D-FLAIR MR imaging findings and 3DFLAIR hyperintensity significantly correlated with vertigo, suggesting extensive inner ear damage ${ }^{6}$; however, other studies reported no significant differences in the initial PTA findings, regardless of abnormalities on MR imaging. ${ }^{7,9}$ Differences in study populations, time intervals between SSNHL onset and MR imaging, and masking effects induced by steroid treatment could explain these differences. ${ }^{6}$ Objective criteria for the presence of high signal intensity on MR images also need to be determined to mitigate any potential differences arising from this issue.

Regarding the prognostic value of abnormalities on labyrinthine MR imaging, recent studies show inconsistent results. Investigations of $3 \mathrm{D}$-FLAIR demonstrated that high signal intensities in the cochlea on precontrast 3D-FLAIR images are associated with a poor prognosis for hearing ${ }^{7,9}$; however, another study showed that hyperintense signals on 3D FLAIR or gadoliniumenhanced MR imaging were not significantly correlated with hearing improvement or posttreatment PTA. ${ }^{6}$

In our study, 3D-FLAIR MR imaging findings closely correlated with the severity of hearing loss. Furthermore, posttreatment hearing levels in the MRI+ group were worse than those of the MRI - group. Moreover, the rate of complete or partial recovery in the MRI - group (34\%) was significantly higher than that of the MR+ group (10\%) when hearing improvement was defined according to the Siegel criteria; however, the MRI+ group might have experienced poor hearing outcomes because they had poorer initial hearing levels than the MRI- group, and patients with a high level of initial HL exhibited a poorer hearing prognosis. ${ }^{7,9}$ Our findings, in which the overall hearing improvement of the MRI+ group $(18 \pm 24 \mathrm{~dB})$ was not significantly worse than that of the MRI- group $(21 \pm 23 \mathrm{~dB})$, support this hypothesis; thus, we analyzed the hearing improvement according to the initial hearing levels and observed that the hearing improvement of the MRI+ group $(23 \pm 24 \mathrm{~dB})$ was significantly less than that of the MRI - group $(38 \pm 27 \mathrm{~dB})$ when the initial hearing loss was severe or profound (Fig 4). Our findings demonstrate that patients with SSNHL with mild or moderate initial HL rarely exhibited abnormalities on labyrinthine MR imaging ( $8 \%, 3$ of 40 ), which were without any significant prognostic value. By contrast, patients with SSNHL with initial severe or profound HL frequently exhibited abnormalities on labyrinthine MR imaging (40\%, 23 of 58), which were significantly associated with a poor prognosis.

Similar findings were reported by using distortion product otoacoustic emissions (DPOAE) in patients with SSNHL. ${ }^{19}$ The function of the outer hair cells as measured by DPOAE, which indicates intact labyrinthine function, was relatively preserved in patients with initial mild-to-moderate HL, and their hearing recovery was not associated with the DPOAE results. This finding is analogous to our findings in which labyrinthine involvement was rare and not related to hearing improvement in patients with initial mild-to-moderate HL; however, patients with preserved DPOAE and initial moderately severe-to-profound HL, who would be analogous to patients with initial severe-or-profound HL in the MRI- group in our study, had a good prognosis.
A large-scale quantitative study involving additional tests, including pure-tone audiometry and DPOAE, may help provide a detailed understanding of the pathophysiology of SSNHL and determine the prognostic value of abnormalities on labyrinthine MR imaging. In this study, we could not correlate MR imaging involvement of different inner ear structures with clinical symptoms because of the small study population.

\section{CONCLUSIONS}

Abnormalities on labyrinthine MR imaging were found in 27\% of patients with SSNHL. Notably, the initial HL in the MRI+ group was worse than that of the MRI- group. In patients with initial severe and profound hearing loss, the presence of an abnormality on labyrinthine MR imaging was a poor prognostic factor. Further studies with a larger study population are needed to clarify the distribution of specific patterns of abnormalities on MR imaging and their clear relationship with hearing improvement.

\section{REFERENCES}

1. Hughes GB, Freedman MA, Haberkamp TJ, et al. Sudden sensorineural hearing loss. Otolaryngol Clin North Am 1996;29:393-405 Medline

2. Schuknecht HF, Donovan ED. The pathology of idiopathic sudden sensorineural hearing loss. Arch Otorhinolaryngol 1986;243:1-15 CrossRef Medline

3. Aarnisalo AA, Suoranta H, Ylikoski J. Magnetic resonance imaging findings in the auditory pathway of patients with sudden deafness. Otol Neurotol 2004;25:245-49 CrossRef Medline

4. Weissman JL, Curtin HD, Hirsch BE, et al. High signal from the otic labyrinth on unenhanced magnetic resonance imaging. AJNR Am J Neuroradiol 1992;13:1183-87 Medline

5. Cervantes SS, Barrs DM. Sudden sensorineural hearing loss associated with intralabyrinthine hemorrhage. Otol Neurotol 2015;36: e134-35 CrossRef Medline

6. Berrettini S, Seccia V, Fortunato S, et al. Analysis of the 3-dimensional fluid-attenuated inversion-recovery (3D-FLAIR) sequence in idiopathic sudden sensorineural hearing loss. JAMA Otolaryngol Head Neck Surg 2013;139:456-64 CrossRef Medline

7. Yoshida T, Sugiura M, Naganawa S, et al. Three-dimensional fluidattenuated inversion recovery magnetic resonance imaging findings and prognosis in sudden sensorineural hearing loss. Laryngoscope 2008;118:1433-37 CrossRef Medline

8. Sugiura M, Naganawa S, Teranishi M, et al. Three-dimensional fluid-attenuated inversion recovery magnetic resonance imaging findings in patients with sudden sensorineural hearing loss. Laryngoscope 2006;116:1451-54 CrossRef Medline

9. Lee HY, Jung SY, Park MS, et al. Feasibility of three-dimensional fluid-attenuated inversion recovery magnetic resonance imaging as a prognostic factor in patients with sudden hearing loss. Eur Arch Otorhinolaryngol 2012;269:1885-91 CrossRef Medline

10. Kim DY, Lee JH, Goh MJ, et al. Clinical significance of an increased cochlear 3D fluid-attenuated inversion recovery signal intensity on an MR imaging examination in patients with acoustic neuroma. AJNR Am J Neuroradiol 2014;35:1825-29 CrossRef Medline

11. Gürkov R, Berman A, Dietrich O, et al. MR volumetric assessment of endolymphatic hydrops. Eur Radiol 2015;25:585-95 CrossRef Medline

12. Wilson WR, Byl FM, Laird N. The efficacy of steroids in the treatment of idiopathic sudden hearing loss: a double-blind clinical study. Arch Otolaryngol 1980;106:772-76 CrossRef Medline

13. Siegel LG. The treatment of idiopathic sudden sensorineural hearing loss. Otolaryngol Clin North Am 1975;8:467-73 Medline

14. Mazzoli M, Van Camp G, Newton V, et al. Recommendations for the description of genetic and audiological data for families with non- 
syndromic hereditary hearing impairment. Audiol Med 2003;1: $148-50$ CrossRef

15. Melhem ER, Jara $H$, Eustace $S$. Fluid-attenuated inversion recovery MR imaging: identification of protein concentration thresholds for CSF hyperintensity. AJR Am J Roentgenol 1997;169:859-62 CrossRef Medline

16. Naganawa S, Komada T, Fukatsu H, et al. Observation of contrast enhancement in the cochlear fluid space of healthy subjects using a 3DFLAIR sequence at 3 Tesla. Eur Radiol 2006;16:733-37 CrossRef Medline

17. Ryu IS, Yoon TH, Ahn JH, et al. Three-dimensional fluid-attenuated inversion recovery magnetic resonance imaging in sudden sensorineural hearing loss: correlations with audiologic and vestibular testing. Otol Neurotol 2011;32:1205-09 CrossRef Medline

18. Noguchi K, Seto H, Kamisaki Y, et al. Comparison of fluid-attenuated inversion-recovery MR imaging with $C T$ in a simulated model of acute subarachnoid hemorrhage. AJNR Am J Neuroradiol 2000; 21:923-27 Medline

19. Park H, Lee Y, Park M, et al. Short-term changes of hearing and distortion product otoacoustic emissions in sudden sensorineural hearing loss. Otol Neurotol 2010;31:862-66 CrossRef Medline 